\title{
Can diabetes with controlled glycemic status cause placental changes and affect foetal outcome? A histomorphology study from a tertiary care centre from Eastern India
}

\author{
Mishra $\mathbf{P}^{1}$, Chakrabarti P. $\mathbf{R}^{2}$ \\ ${ }^{1}$ Dr Poonam Mishra, Assistant Professor, Department of Pathology, Sukh Sagar Medical College and Hospital, Jabalpur, \\ MP, ${ }^{2}$ Dr Preeti Rihal Chakrabarti, Associate Professor, Department of Pathology, Sri Aurobindo Medical College \& PG \\ Institute, MP, India.
}

Address for Correspondence: Dr Preeti Rihal Chakrabarti, Email: preetirihal@ yahoo.co.in

\begin{abstract}
Background: Normal foetal development and postnatal survival depends on healthy placenta. The adverse effects of diabetes on pregnancy and related foetal outcomes are well established and through this study we have attempted to study the intensity of damage caused, by examining the gross and microscopic features of placenta along with histochemical changes. Material and Methods: This was a prospective study undertaken in a tertiary teaching hospital in which a total of 80 cases of term pregnancy were studied, out of which 40 were from diabetic mothers and 40 were from non diabetic mothers. Biochemical parameters of all the cases were studied. All placenta were examined on the basis of gross features, histological \& histochemical changes. Results: In the present study, it was noted that gross morphology of placenta was not much altered between diabetic and normal mothers but showed marked variation in the histological findings. On microscopic examination, marked basement membrane thickening, vascular proliferation, chorangiosis, syncytial knots, villous fibrosis and edema were noted among diabetic mothers and most common postnatal complication of newborns among diabetic mothers was macrosomia. Conclusion: This study highlights the impact of gestational and pregestational diabetes mellitus on placenta as observed by the magnitude of histological changes inspite of having controlled glycemic status either by diet or insulin and associated postnatal morbidities of newborns.
\end{abstract}

Keywords: Diabetes Mellitus, Placenta histopathology, Biochemical parameter

\section{Introduction}

The placenta is a vital in-utero organ that separates the maternal and fetal circulations, transfers nutrients, waste products and plays a central metabolic role in pregnancy [1]. Placental pathology is always associated with certain fetal complications, so examination of placenta is subject of fascinations for pathologist.

It reflects prenatal health status of the baby, mother and is a mirror which reflect the intrauterine status of the fetus [2]. At term, the Placentae of diabetic mothers show number of variation when compare to placentae of non diabetic mothers e.g heavier placenta and immature villi $[3,4]$. Diabetes mellitus (DM) in pregnant women

Manuscript received: $6^{\text {th }}$ January 2017

Reviewed: $15^{\text {th }}$ January 2017

Author Corrected: $22^{\text {nd }}$ January 2017

Accepted for Publication: $28^{\text {th }}$ January 2017 may be categorize into clinical diabetes or pregestational diabetes (women previously diagnosed with type I \& type II diabetes) and gestational diabetes (GDM), which is defined as any degree of glucose intolerance first recognized during pregnancy.

Maternal glucose intolerance is detected in $3-10 \%$ of pregnancy [5]. Hence in present study an attempt was made to investigate the histopathological changes in placenta of pregnancies complicated by diabetes with controlled diabetic status as compared to normal pregnancies and to enrich our knowledge with respect to histochemical changes.

To the best of our knowledge, there is scarcity of published literature from an eastern Indian population. 


\section{Aims and objectives}

1. To measure the clinical, obstetrical and biochemical parameters among the study population.

2. To measure the postnatal parameter of the babies of the study population.

3. To find out the pathological features (microscopic and macroscopic) of the placenta of study population.

4. To compare histopathological changes of placenta between diabetic and normal mothers and related foetal outcomes.

\section{Materials and Methods}

This study was done in the Department of Pathology in collaboration with Department of Obstetrics \& Gynaecology of the tertiary care teaching hospital, Kolkata during the period from January 2011 to June 2012. Total 80 placentae were analysed, 40 were from diabetic mothers and 40 were from uncomplicated full term deliveries. The diabetic placenta served as study groups and non-diabetic placenta as control groups. Inclusion criteria consisted of all pregnant mothers complicated with diabetes irrespective of their type, clinical data, specimen of placenta. Exclusion criteria comprised of diabetic pregnant mothers with additional complications like toxaemia of pregnancy, antepartum haemorrhage or RH incompatability. Patient lost or missing in the follow-up period were excluded from the study. Clinical, haematological, biochemical parameters of mothers \& postnatal outcomes of their newborn were studied. The placenta with intact membranes and umbilical cord were collected immediately after delivery, washed in running tap water and then fixed with $10 \%$ formalin for 24 hours. Gross features of placenta were examined including size, shape, weight, thickness at centre, number of cotyledons, and site of insertion of umbilical cord. Microscopic examination was carried out after staining with hematoxylin \& eosin $(H \&$ E) and special stains like periodic acid Schiff (PAS) and van Gieson (VG). Histopathological changes of placentae of diabetic mothers and that of normal mothers were compared and analysed. Relationships of placental changes with fetal outcomes were also assessed. Statistical analysis of the data was done on SPSS (Statistical package for social science) for windows, version 20. Pearson Chi-square tests were used to assess differences in the morphological features between two groups. Results were considered significant when the $\mathrm{p}$ value was less than 0.05 . Numerical variables between groups were analysed using the student $\mathrm{T}$ test.

\section{Results}

Out of 80 patients in present study, 40 were diabetic and 40 were non-diabetic. Among the 40 diabetic patients, maximum number of diabetic mothers belonged to GDM 38 (95\%), 2 cases were Type 2 DM and none from Type 1 DM. Among diabetic mothers, maximum cases were multipara 27 (67.5\%) in comparison to normal pregnant mothers 06 (15\%). Table 1 displays the biochemical parameters of our study population which shows statistically significant higher values of fasting LDL among diabetic mothers \& normal mothers as $126.93 \pm 37.28 \& 95.88 \pm 10.76$ respectively. Both diabetic and non-diabetic mothers had encountered various complications in newborns as macrosomia, jaundice, hypoglycemia, respiratory distress syndrome (RDS) \& Neonatal intensive care unit admission. Macrosomia was most common complications among newborns of diabetic and non-diabetic mothers. [Table 2] Gross examination showed no significant differences among the two groups except the weight of placenta which was more in diabetic as compared to normal mothers. Histopathological examination of placentae of both the groups showed significant changes with commonest findings as basement membrane thickening of villi of placentae of diabetic mothers 32 (80\%) in comparison to normal mothers and the difference was statistically significant [Table 3]. Histochemical stains like PAS confirmed marked thickening of basement membrane [Fig.1] and VG stain confirmed fibrosis [Fig.2].

Table-1: Comparison of biochemical profile among diabetic mothers and normal mothers $(\mathrm{N}=80)$.

\begin{tabular}{|c|c|c|}
\hline Biochemical profile & $\begin{array}{c}\text { Diabetic mother } \\
\text { Mean(mg/dl) } \pm \text { SD, } \mathbf{( N - 4 0 )}\end{array}$ & $\begin{array}{c}\text { Normal mother } \\
\text { Mean(mg/dl) } \mathbf{S D}, \mathbf{( N - 4 0 )}\end{array}$ \\
\hline Total Cholesterol & $222.73 \pm 48.77$ & $179.88 \pm 14.74$ \\
\hline HDL & $46.03 \pm 9.82$ & $48.78 \pm 7.06$ \\
\hline LDL & $126.93 \pm 37.28$ & $95.88 \pm 10.76$ \\
\hline HbA1C & $5.66 \pm 1.33$ & $4.96 \pm 0.27$ \\
\hline
\end{tabular}


Table-2: Comparison of postnatal complications in babies of diabetic and normal mothers.

\begin{tabular}{|c|c|c|}
\hline Complications & Diabetic(N-40) & Normal (N-40) \\
\hline Macrosomia & $9(22.5 \%)$ & $3(7.5 \%)$ \\
\hline Jaundice & $5(12.5 \%)$ & $0(0 \%)$ \\
\hline Congenital malformations & $0(0 \%)$ & $0(0 \%)$ \\
\hline Hypoglycemia & $3(7.5 \%)$ & $1(2.5 \%)$ \\
\hline Sepsis & $1(2.5 \%)$ & $0(0 \%)$ \\
\hline R.D.S & $1(2.5 \%)$ & $4(10 \%)$ \\
\hline NICU admission & $6(15 \%)$ & $1(2.5 \%)$ \\
\hline Mortality & $2(5 \%)$ & \\
\hline
\end{tabular}

Table-3: Showing comparison of microscopic findings in placenta of diabetic mothers and normal mothers(N=80)

\begin{tabular}{|c|c|c|c|c|}
\hline Mic roscopic findings & Total & Diabetic (40) & Normal (40) & Significance \\
\hline $\begin{array}{c}\text { B.M } \\
\text { Thickening }\end{array}$ & $33(41.2 \%)$ & $32(80 \%)$ & $01(2.5 \%)$ & P-value $<0.05$ \\
\hline $\begin{array}{c}\text { Fibrinoid } \\
\text { Necrosis }\end{array}$ & $40(50.0 \%)$ & $35(87.5 \%)$ & $5(12.5 \%)$ & P-value $<0.05$ \\
\hline $\begin{array}{c}\text { Syncytial } \\
\text { Knots }\end{array}$ & $40(50 \%)$ & $34(85 \%)$ & $06(15 \%)$ & P-value $<0.05$ \\
\hline $\begin{array}{c}\text { Villous fibrosis } \\
\text { (Increased villous vascularity) }\end{array}$ & $11(13.8 \%)$ & $11(27.5 \%)$ & $00(00 \%)$ & P-value $<0.05$ \\
\hline Villous oedema & $22(27.5 \%)$ & $20(50 \%)$ & $02(05 \%)$ & P-value $<0.05$ \\
\hline $\begin{array}{c}\text { Villous } \\
\text { hofbauer cells }\end{array}$ & $21(26.2 \%)$ & $19(47.5 \%)$ & $02(05 \%)$ & P-value $<0.05$ \\
\hline $\begin{array}{c}\text { Stromal } \\
\text { Calcification }\end{array}$ & $16(20.0 \%)$ & $7(17.5 \%)$ & $9(22.5)$ & \\
\hline Total & & & & \\
\hline
\end{tabular}

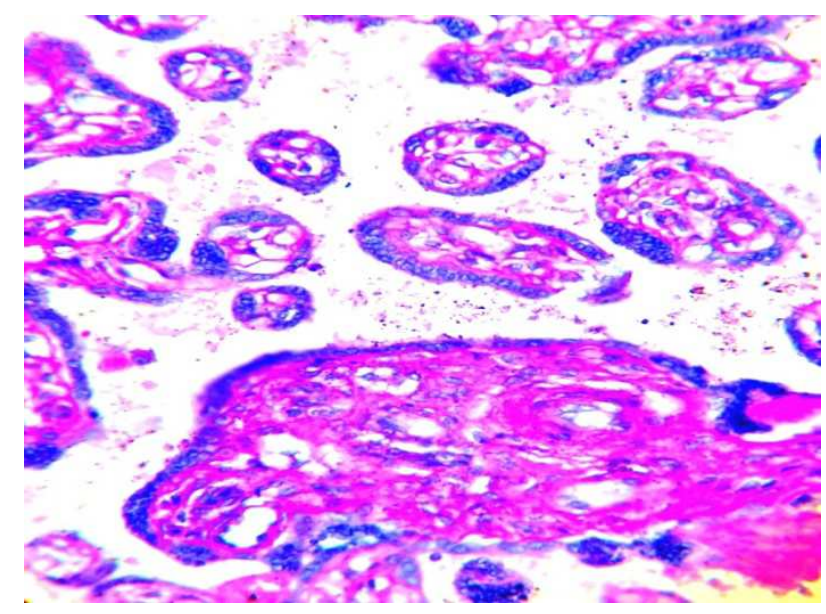

Figure-1: High power view showing basement membrane thickening of villi of placenta in diabetic patients (PAS stain, X400)

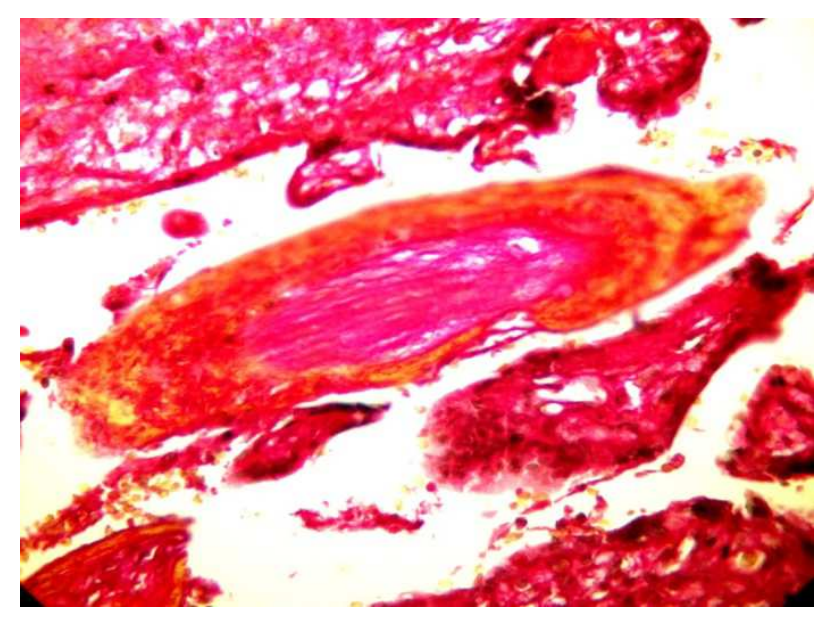

Figure-2: High power view showing villous fibrosis of placenta in diabetic patients (VG stain, X400). 


\section{Discussion}

In the present study, mean age of diabetic patients was $28.88 \pm 2.95$ and normal mothers were $26.03 \pm 3.04$. Among diabetic mothers $82.5 \%$ of diabetic patients were above 30 years of age and among them maximum were multiparous 27 $(67.5 \%)$. Our findings showed that increasing maternal age and parity were associated with increased risk of diabetes in pregnancy which was in concordance with previous studies [6,7]. Maximum number of patients 38 (95\%) affected with diabetes were of GDM type and $2(5 \%)$ were of type 2 DM. Total cholesterol and LDL cholesterol in GDM mothers were significantly increased $(\mathrm{p}<0.05)$ in comparison to normal mothers whereas HDL cholesterol was similar between these two groups and it was in concordance with the previous study. [8]

In the present study, commonest complications encountered in newborns of the diabetic mothers were macrosomia 9 (22.5\%) followed by jaundice $5(12.5 \%)$ and hypoglycaemia 3 (7.5\%). The reported incidence of macrosomia in women with GDM is 16-29\% as opposed to a 7.5\% rate in women without GDM [9,10]. However in another study, by Alam M et al, hypoglycaemia (15-20\%) and jaundice (25\%) were commonest complications [11]. Neonatal hypoglycemia is less frequent when tight glycemic control is maintained during pregnancy and in labor [12]. This explains the lower incidence of hypoglycemia in our study probably due to strict glycemic control. In babies of normal mothers, $3(75 \%)$ infants were sent to N.I.C.U due to hyperbilirubinemia but none required phototherapy; and $1(25 \%)$ infant sent to NICU died due to sepsis. On gross examination, it was observed that mean weight of placenta of diabetic mother was slightly higher (557.90 \pm 56.50$)$ as compared to the control group $(487.88 \pm 25.40)$. The cause of slightly higher weight is probably due to controlled glycemic status of pregnant diabetic mothers and the exclusion of cases which showed signs of vascular compromise as seen in hypertensive cases. In another study, done by Maksheed et al., it was observed that the placental weight and neonatal weight were increased, provided the diabetes was not complicated with vascular disease [13]. The mean placental diameter in diabetic group was $19.77 \pm 2.76$ and in control group was $16.02 \pm 1.02$ and the results were statistically significant ( $\mathrm{p}$-value $<0.05$ ) in our study which was also in concordance with study by Aladjem et al [14].

On microscopic examination, increased basement membrane thickening of villi was present in $80 \%$ of diabetic placentae whereas in normal placentae it was present only in $2.5 \%$ of cases, which showed significant differences in between the two groups. Al-okail et al., in their study, showed marked thickening of basement membrane of villi in placentae of uncontrolled GDM, mild thickening was observed in well controlled diabetic placentae, and in normal placentae there was complete absent of basement thickening [15]. In another study by Tewari et al, 100\% of diabetic placentae also showed similar findings [16]. Our observation showed slightly lower values than previous studies because of the facts that most cases in our study were controlled diabetics mothers. Chorangiosis was another significant finding found in $27.5 \%$ of diabetic placentae [Fig 3] whereas it was totally absent in placentae of normal mothers. According to another study by Margaret $\mathrm{J}$ Evans, chorangiosis is found in about a third of diabetic pregnancies and show significant association with poor glycaemic control [17]. Dysregulation of growth factors and their receptors may be responsible for placental and fetal changes in diabetes like enhanced growth and hypervascularization [18].

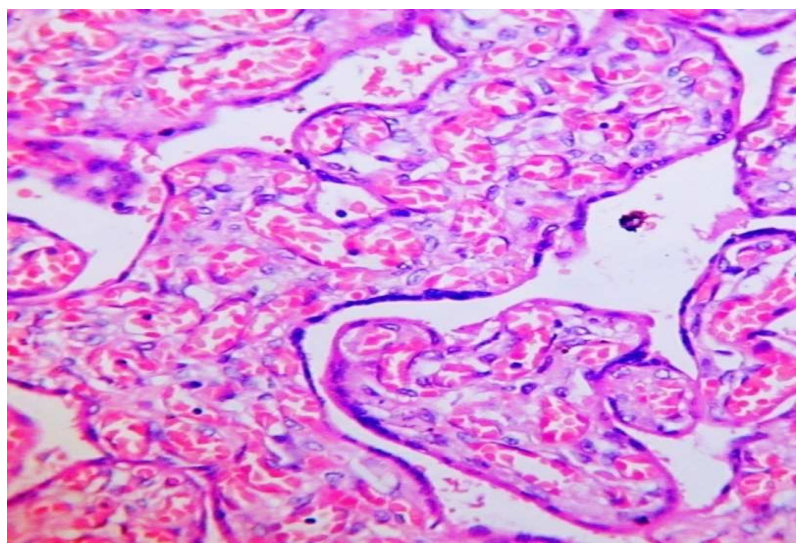

Figure-3: High power view showing chorangiosis of villi of placenta in diabetic patients (H \& E stain, X400)

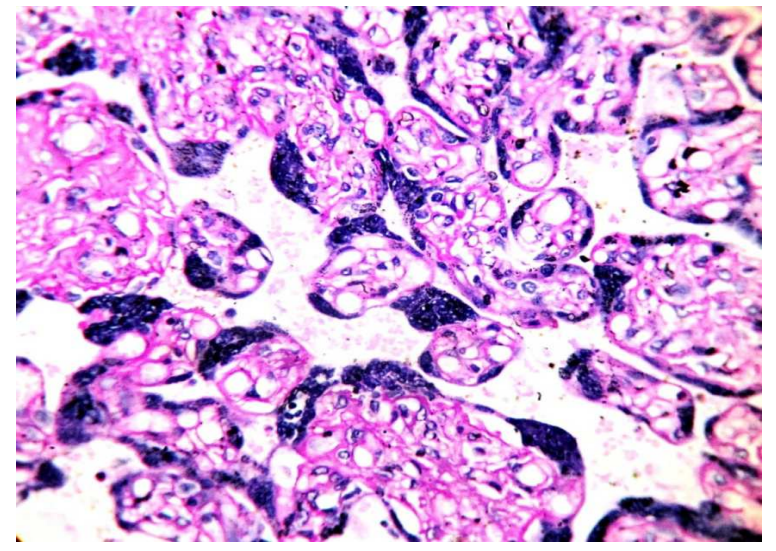

Figure-4: Low power view showing syncytial knots in villi of placenta in diabetic patients (H \& E stain, X100) 


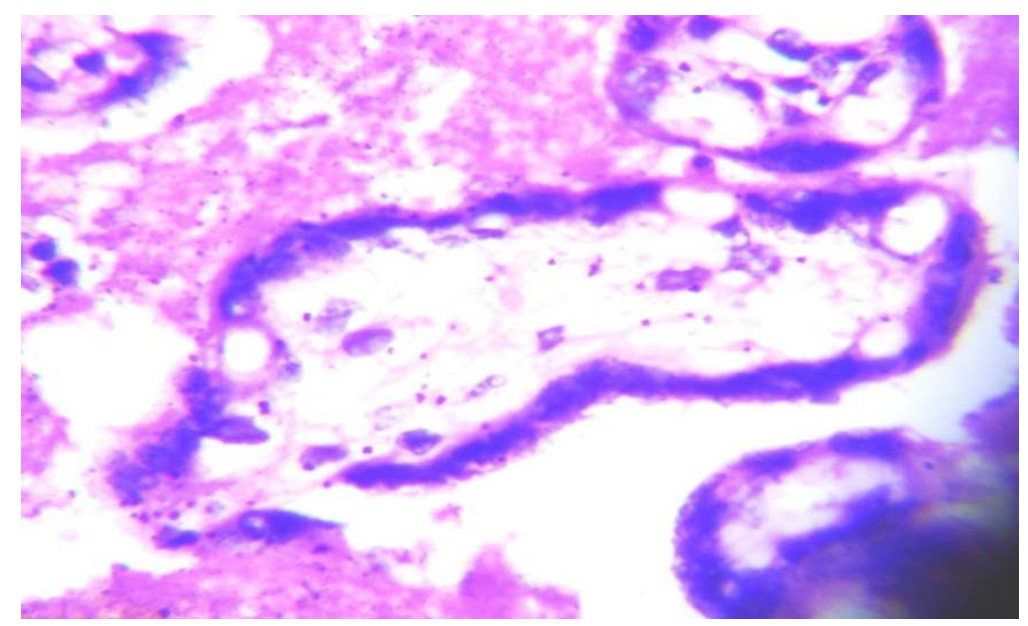

Figure-5: High power view showing villous oedema of placenta in diabetic patients (H \& E stain, X400)

A significant increase in syncytial knots [Fig4] formation was noted in villi of diabetic placentae (85\%) in comparison to placentae of control group (15\%) and our results were consistent with the findings of previous studies [5]. Villous oedema [Fig 5] was observed in 50\% of diabetic placentas and only 05\% in normal placentas. According to Al-okail et al, villous edema was observed in placenta of diabetic mothers, more obvious in gestational diabetes [15]. Villous Hofbauer cells $(47.5 \%)$ and villous fibrosis (30\%) were other findings observed in diabetic placenta more than in normal placentas in present study. According to H Fox, villi of diabetic placenta showed marked fibrosis and increase Hofbauer cells [19]. Tewari et al., [16] in their study, found increase incidence of fibrosis in diabetic pregnancy and similar findings were also reported by Gheorman et al [20].

\section{Conclusion}

In the backdrop of paucity of studies in literature arising from eastern part of India, our study highlights the impact of maternal diabetes on the developing placenta with respect to controlled glycemic status and its effect on foetal outcome. We call for further research in this aspect to ascertain and analyse a possible etiopathogenesis of placental changes despite of clinically controlled diabetic status.

\section{Funding: Nil, Conflict of interest: None Permission of IRB: Yes}

\section{References}

1. Hay WW Jr, Catz CS, Grave GD, Yaffe SJ. Workshop summary: fetal growth: its regulation and disorders. Pediatrics. 1997 Apr;99(4):585-91.

2. Udainia A, Jain ML. Morphological study of placenta in pregnancy induced hypertension with its clinical relevance. J Anat Soc India. 2001;50(1):24-7.

3. Taricco E, Radaelli T, Nobile de Santis MS, Cetin I. Foetal and placental weights in relation to maternal characteristics in gestational diabetes. Placenta. 2003 Apr;24(4):343-7.
4. Daskalakis G, Marinopoulos S, Krielesi V, Papapanagiotou A, Papantoniou N, Mesogitis S, Antsaklis A. Placental pathology in women with gestational diabetes. Acta Obstet Gynecol Scand. 2008; 87 (4): 403-7. doi: 10.1080/00016340801908783.

5. Treesh SA, Khair NS. Histological changes of the human placenta in pregnancies complicated with diabetes. Journal of Cytology \& Histology. 2015 Feb $15 ; 6(2): 1$.

6. Kheir AE, Berair R, Gulfan IG, Karrar MZ, Mohammed ZA. Morbidity and mortality amongst infants of diabetic mothers admitted into Soba university hospital, Khartoum, Sudan. Sudan J Paediatr. 2012;12(1):49-55.

7. Farooq MU, Ayaz A, Bahoo A, Ahmad I. Maternal and neonatal outcomes in gestational diabetes mellitus. International Journal of Endocrinology and Metabolism. 2007 Sep;2007(3, Summer):109-15.

8. Toescu V, Nuttall SL, Martin U, Nightingale P, Kendall MJ, Brydon P, Dunne F. Changes in plasma lipids and markers of oxidative stress in normal 
pregnancy and pregnancies complicated by diabetes. Clin Sci (Lond). 2004 Jan;106(1):93-8.

9. Naylor CD, Sermer M, Chen E, Sykora K. Cesarean delivery in relation to birth weight and gestational glucose tolerance: pathophysiology or practice style? Toronto Trihospital Gestational Diabetes Investigators. JAMA. 1996 Apr 17;275(15):1165-70.

10. Lu GC, Rouse D, Dubard M, Cliver S. The impact of lower threshold values for the detection of gestational diabetes mellitus. Obstetrics \& Gynecology. 2000 Apr 30;95(4):S44.

11. Alam M, Raza SJ, Sherali AR, Akhtar AS. Neonatal complications in infants born to diabetic mothers. J Coll Physicians Surg Pak. 2006 Mar;16(3):212-5.

12. Banerjee S, Ghosh US, Banerjee D. Effect of tight glycaemic control on fetal complications in diabetic pregnancies. J Assoc Physicians India. 2004 Feb;52: 109-13.

13. Makhseed M, Musini VM, Ahmed MA, Al-Harmi J. Placental pathology in relation to the White's classification of diabetes mellitus. Arch Gynecol Obstet. 2002 Jul;266(3):136-40.

14. Aladjem S. Morphologic aspects of the placenta in gestational diabetes seen by phase-contrast microscopy. An anatomicoclinical correlation. American journal of obstetrics and gynecology. 1967 Oct;99(3):341-9.
15. al-Okail MS, al-Attas OS. Histological changes in placental syncytiotrophoblasts of poorly controlled gestational diabetic patients. Endocr J. 1994 Aug; 41 (4):355-60.

16. Tewari V, Tewari A, Bhardwaj N. Histological and histochemical changes in placenta of diabetic pregnant females and its comparision with normal placenta. Asian Pacific Journal of Tropical Disease. 2011 Mar $1 ; 1(1): 1-4$.

17. Evans MJ. Review: Diabetes and pregnancy: a review of pathology. The British Journal of Diabetes \& Vascular Disease. 2009 Sep;9(5):201-6.

18. Hiden U, Glitzner E, Ivanisevic M, Djelmis J, Wadsack C, Lang U, Desoye G. MT1-MMP expression in first-trimester placental tissue is upregulated in type 1 diabetes as a result of elevated insulin and tumor necrosis factor-alpha levels. Diabetes. 2008 Jan;57 (1):150-7. Epub 2007 Oct 10.

19. Jones CJ, Fox H. Placental Changes in Gestational Diabetes: An Ultrastructural Study. Obstetrics \& Gynecology. 1976 Sep 1;48(3):274-80.

20. Gheorman L, Pleşea IE, Gheorman V. Histopathological considerations of placenta in pregnancy with diabetes. Rom J Morphol Embryol. 2012; 53 (2):329-36.

\section{How to cite this article?}

Mishra P, Chakrabarti P. R. Can diabetes with controlled glycemic status cause placental changes and affect foetal outcome? A histomorphology study from a tertiary care centre from Eastern India. Int J Med Res Rev 2017;5(03):273278 doi:10.17511/ijmrr. 2017.i03.10. 